\title{
Efeito da umidade sobre a microestrutura da inulina em pó
}

\author{
Effect of moisture on the microstructure of inulin powder
}

Juliana Tófano de Campos Leite TONELI ${ }^{1,3 *}$, Kil Jin PARK ${ }^{1}$, Fernanda Elizabeth Xidieh MURR², Alessandra Alves NEGREIROS ${ }^{2}$

\begin{abstract}
Resumo
A aplicação da inulina nas indústrias de alimentos e farmacêuticas está associada à possibilidade de substituição do açúcar e da gordura, com baixa contribuição calórica, e na formulação de medicamentos e alimentos funcionais, pois atua no organismo de maneira similar às fibras dietéticas. A comercialização da inulina é feita preferencialmente com o produto em pó, devido à maior facilidade no transporte, embalagem e manuseio. Dessa forma, é de grande importância conhecer o comportamento do produto quando armazenado sob diferentes condições de umidade relativa. O objetivo desse trabalho foi o de avaliar a influência da umidade sobre a microestrutura da inulina em pó, obtida a partir da secagem por atomização de um concentrado de inulina extraído de raízes de chicória. A análise da estrutura do material em microscópio eletrônico de varredura demonstrou a sua elevada higroscopicidade. Em ambientes com atividade de água (a $)$ superior a 0,3085, a inulina sofreu alterações em sua microestrutura que comprometeram a sua qualidade. Ao ser armazenada em ambiente com $\mathrm{a}_{\mathrm{w}}=0,5285, \mathrm{o}$ material perdeu suas características de pó, devido à aglomeração de partículas associada à absorção de umidade, e se transformou em uma massa sólida. Essa característica foi agravada com o aumento da umidade relativa do ambiente.

Palavras-chave: microscopia eletrônica de varredura; atividade de água; spray dryer.
\end{abstract}

\begin{abstract}
The application of inulin in food and pharmaceutical industries is associated to the possibility of substituting sugar or fat, with a low caloric contribution, and of formulating medicine and functional foods, as it acts in the human organism in a similar way to dietary fibers. Inulin is mostly commercialized as a powder, which provides easier manipulation, transportation, storage and consumption. Thus, it is of great importance to know the behavior of inulin powder when stored under different relative humidity conditions. The objective of this work was to evaluate the influence of moisture on the microstructure of inulin powder, obtained from spray drying an inulin concentrate extract from chicory roots. The analysis of the structure of the material in a scanning electron microscope demonstrated its high higroscopicity. In environments with water activity $\left(\mathrm{a}_{\mathrm{w}}\right)$ higher than 0.3085 , inulin presented alterations in its microstructure that compromised its quality. When inulin was stored in an environment with $\mathrm{a}_{\mathrm{w}}=0.5285$, the material lost its powder characteristics, due to particle agglomeration associated to moisture absorption, and it turned into a solid mass. This characteristic was aggravated with the increase of the relative humidity of the environment.
\end{abstract}

Keywords: scanning electron microscopy; water activity; spray dryer.

\section{Introdução}

A inulina é um carboidrato de reserva naturalmente presente em mais de 30.000 vegetais, formado por uma cadeia de moléculas de frutose e uma molécula de glicose terminal. Dentre esses produtos, as raízes de chicória (Cichorium intybus) e de alcachofra de Jerusalém (Helianthus tuberosus) se destacam para a sua produção em escala industrial (SILVA, 1996).

A aplicação da inulina na indústria de alimentos deve-se, principalmente, às propriedades que a tornam capaz de substituir o açúcar ou a gordura, com a vantagem de não resultar em incremento calórico. Pode-se, desse modo, empregá-la como ingrediente em uma série de alimentos, tais como chocolates, sorvetes, iogurtes, dentre outros. Sua utilização em produtos com baixa caloria e teor de gordura reduzido já é bastante difundida em países da Europa, nos Estados Unidos e no Canadá.
Outra característica importante da inulina está associada às suas propriedades nutricionais, atuando no sistema digestivo de maneira similar às fibras dietéticas, contribuindo para o incremento dos benefícios das bifidobactérias e, conseqüentemente, para a melhoria das condições de todo o sistema gastrintestinal. Devido a essas propriedades, a indústria alimentícia e a farmacêutica têm encontrado aplicações para a inulina na produção de alimentos funcionais, compostos nutritivos e medicamentos (ROBINSON, 1995; O'BRIEN et al., 2003).

Os métodos convencionalmente utilizados para extrair inulina de raízes de chicória incluem algumas etapas básicas: lavagem dos tubérculos; fatiamento ou moagem dos tubérculos; extração de inulina com água; tratamento do extrato com dióxido de carbono e cal; filtragem e recuperação da inulina por

Recebido para publicação em 22/9/2006

Aceito para publicaçào em 17/12/2007 (001859)

${ }^{1}$ Faculdade de Engenharia Agrícola, Universidade Estadual de Campinas - UNICAMP, CP 6011, CEP 13084-971, Campinas - SP, Brasil, E-mail: juliana@agr.unicamp.br

${ }^{2}$ Faculdade de Engenharia de Alimentos, Universidade Estadual de Campinas - UNICAMP, CP 6121, CEP 13083-970, Campinas - SP, Brasil,

E-mail:fexmurr@fea.unicamp.br

${ }^{3}$ Centro de Engenharia, Modelagem e Ciências Sociais Aplicadas, Universidade Federal do ABC - UFABC, Rua Santa Adélia, 166, Bairro Bangu, CEP 09210-170,

Santo André - SP, Brasil

${ }^{*}$ A quem a correspondência deve ser enviada 
precipitação ou evaporação (LAURENZO; NAVIA; NEIDITCH, 1999).

A inulina é um carboidrato solúvel em água, com solubilidade dependente da temperatura. À temperatura de $10{ }^{\circ} \mathrm{C}$, a solubilidade da inulina é de $6 \%$, ao passo que a $90{ }^{\circ} \mathrm{C}$, ela cresce para aproximadamente 35\% (SILVA, 1996). Por essa razão, quando a inulina é resfriada ou congelada, ocorre uma precipitação dos frutooligossacarídeos, provocada pela redução da temperatura.

Baseando-se nessas características da inulina, Park et al. (2000) propuseram um processo para obtenção de um concentrado de inulina, utilizando a técnica de abaixamento de temperatura e posterior separação física. No processo a inulina é extraída das raízes de chicória por difusão em água quente. $\mathrm{O}$ extrato obtido é então filtrado e concentrado por evaporação. $\mathrm{O}$ extrato concentrado é levado a uma câmara de congelamento (com temperaturas entre $-8 \mathrm{e}-50^{\circ} \mathrm{C}$ ), onde ocorre decantação. Após descongelamento dos extratos, é feita a separação física entre as fases sobrenadante (líquida) e precipitada (semelhante a um creme), obtidas pelo abaixamento de temperatura do extrato.

Leite (2001) estudou o processo proposto em Park et al. (2000) e verificou que o congelamento do extrato líquido de inulina à temperatura de $-15^{\circ} \mathrm{C}$ originou um precipitado mais rico em inulina do que o resfriamento do extrato a $8{ }^{\circ} \mathrm{C}$ ou o congelamento do mesmo a $-11^{\circ} \mathrm{C}$, o qual pode ser levado ao spray dryer para a obtenção do produto em pó. Toneli et al. (2006) verificaram que o congelamento do extrato concentrado de inulina, à temperatura de $-24^{\circ} \mathrm{C}$, seguido pelo descongelamento à temperatura ambiente e centrifugação à velocidade de $10.000 \mathrm{rpm}$ durante 15 minutos, resultou em um processo com elevado rendimento de precipitação de inulina.

A comercialização da inulina é realizada preferencialmente com o produto em pó, obtido através da secagem por atomização (spray dryer). Essa escolha está relacionada às facilidades de manipulação, transporte, armazenamento e consumo.

Para que haja um bom rendimento no processo de secagem por atomização, é necessário que o processo de extração resulte em um extrato líquido com alta concentração de inulina. Ao final do processo de secagem, é preciso conhecer as propriedades do pó resultante, de forma que seja possível avaliar a influência dos parâmetros de secagem sobre as características e sobre a estabilidade do produto final.

Durante a armazenagem, os alimentos são expostos a condições de temperatura e umidade relativa variadas. Nessas condições, eles perdem ou ganham água para ajustar a sua umidade ao equilíbrio com o ambiente. Quando a umidade da inulina em pó varia, algumas alterações físicas, tais como a aglomeração ou o endurecimento, podem ocorrer (SCHALLER-POVOLNY; SMITH; LABUZA, 2000). Com a finalidade de determinar e compreender as alterações nas propriedades físico-químicas relacionadas à absorção de água, alguns parâmetros físicos podem ser avaliados (RONKART et al., 2006).
A microscopia eletrônica de varredura tem se mostrado uma ferramenta eficiente para determinação e observação do fenômeno de aglomeração que ocorre na superfície de polissacarídeos. Entretanto, a literatura sobre a utilização dessa técnica aplicada a biopolímeros é muito escassa (RONKART et al., 2006). Ronkart et al. (2006) utilizaram a microscopia eletrônica de varredura ambiental para estudar a alteração estrutural sofrida pela inulina comercial em pó quando armazenada em ambientes com atividades de água variadas.

Esse trabalho teve como principal objetivo avaliar a microestrutura do precipitado de inulina em pó, através da microscopia eletrônica de varredura, quando armazenado sob diferentes condições de umidade relativa, à temperatura de $25^{\circ} \mathrm{C}$, até o equilíbrio.

\section{Metodologia}

\subsection{Obtenção do precipitado de inulina}

O extrato líquido de inulina foi obtido a partir de raízes de chicória cultivadas no campo experimental da Faculdade de Engenharia Agrícola/Unicamp em março de 2003 e colhidas em outubro do mesmo ano. As raízes foram colhidas, lavadas, fatiadas e moídas. A extração da inulina foi realizada por difusão em água quente, na proporção de $1 \mathrm{~kg}$ de raiz: $2 \mathrm{~kg}$ de água, à temperatura de $80^{\circ} \mathrm{C}$ durante 1 hora, com agitação constante. $\mathrm{O}$ extrato resultante foi filtrado e levado a um evaporador a vácuo para concentração. $\mathrm{O}$ processo de concentração foi efetuado à temperatura de $70^{\circ} \mathrm{C}$, com vácuo de 15 pol de $\mathrm{Hg}$, até a concentração de $22^{\circ} \mathrm{Brix}$.

Para o processo de secagem, foi utilizado o precipitado de inulina resultante da separação física por abaixamento de temperatura, de acordo com a metodologia descrita em Leite (2001). Para tal, o extrato concentrado de inulina foi congelado à temperatura de $-24^{\circ} \mathrm{C} \mathrm{e}$, em seguida, descongelado à temperatura ambiente $\left(25^{\circ} \mathrm{C}\right)$. Após o degelo, a separação física foi realizada manualmente, despejando-se cuidadosamente o sobrenadante em outro recipiente, sem o auxílio de qualquer material.

\subsection{Secagem por atomização}

A secagem do precipitado de inulina foi realizada em um secador laboratorial com sistema de atomização em bicos (mini spray dryer), marca BÜCHI, modelo B191, disponível no Laboratório de Tecnologia Pós-colheita/Secagem da Faculdade de Engenharia Agrícola/UNICAMP. A alimentação do secador é realizada através de uma bomba peristáltica, cuja velocidade de rotação pode ser ajustada em função da velocidade máxima, que corresponde a uma taxa de secagem de 1,5 kg de água/hora.

$\mathrm{O}$ processo de secagem foi realizado à temperatura de $210{ }^{\circ} \mathrm{C}$, com o precipitado mantido à temperatura de $25^{\circ} \mathrm{C}$ na alimentação, que foi conduzida a $5 \%$ da velocidade máxima da bomba peristáltica. O fluxo de ar comprimido foi mantido constante a 600 L/hora e utilizou-se $70 \%$ da capacidade máxima do aspirador. Essas condições foram estabelecidas de acordo com Toneli (2006). 


\subsection{Estudo da estabilidade da inulina em pó}

\section{Umidade de equilíbrio}

As amostras de cerca de $4 \mathrm{~g}$ de precipitado de inulina em pó foram colocadas em recipientes com umidade relativa controlada, e armazenadas em estufa à temperatura de $25^{\circ} \mathrm{C}$, até que atingissem o equilíbrio. Foram avaliados diferentes ambientes com atividade de água variável entre 0,08 e 0,95, através do preparo de soluções saturadas de sais, conforme pode ser observado na Tabela 1.

O ponto de equilíbrio foi determinado através da realização de pesagens sucessivas das três amostras de aproximadamente $1 \mathrm{~g}$ de precipitado de inulina em balança analítica, até que houvesse uma estabilização da massa na quarta casa decimal. Uma vez atingido o equilíbrio, as amostras foram levadas a uma estufa a vácuo, à temperatura de $70{ }^{\circ} \mathrm{C}$ por 72 horas, com pressão negativa de 25 pol de $\mathrm{Hg}$, para determinação da umidade, de acordo com o método $\mathrm{n}^{\circ}$ 44.1.01 da ASSOCIATION OF OFFICIAL ANALYTICAL CHEMISTS (1995).

\section{Análise da microestrutura}

Após o equilíbrio ter sido atingido, uma pequena porção do material foi retirada e levada ao microscópio eletrônico de varredura (MEV) para análise da microestrutura.

As diferentes amostras do extrato de chicória em pó foram fixadas em porta-espécimens metálicos (stubs) de $12 \mathrm{~mm}$ de diâmetro e $10 \mathrm{~mm}$ de altura. A fixação foi realizada através do uso de uma fita adesiva de dupla face convencional, a qual foi previamente aplicada no stub e pressionada para eliminar as rugosidades. Em seguida, as amostras foram coladas na parte superior da fita. Por se tratar de produto em pó, houve necessidade de se remover o excesso de amostra, para evitar que parte dela se soltasse durante a visualização no MEV. Para remoção do excesso, utilizou-se uma pipeta automática.

Uma vez que as amostras analisadas não eram metálicas, houve necessidade de se realizar uma metalização (sputtering), cobrindo-as com uma camada fina de metal para evitar o efeito de charging up durante a observação no microscópio eletrônico. Com essa finalidade, realizou-se uma cobertura com ouro, utilizando o processo de evaporação de ouro a vácuo no metalizador Sputter Coater Balzers SCD050, disponível no Laboratório de Microscopia Eletrônica do Instituto de Biologia (IB/UNICAMP). Para a metalização, foi aplicada uma corrente de $40 \mathrm{~mA}$ durante 180 segundos, tendo como gás de arraste o argônio a um vácuo de 0,05 mbar.

As amostras metalizadas foram mantidas em um suporte fechado, dentro de um dessecador, até o momento da análise no microscópio eletrônico de varredura.

O microscópio eletrônico de varredura utilizado para visualização das amostras foi o MEV JSM - 5800LV - JEOL, disponível no Laboratório de Microscopia Eletrônica do Instituto de Biologia (IB/UNICAMP). Foram avaliadas as imagens geradas pelos elétrons secundários, acelerados a uma tensão de $5 \mathrm{kV}$. As imagens foram capturadas na forma digital.

O tamanho das partículas foi determinado através de medida direta do diâmetro das estruturas esféricas fornecidas pelo microscópio com um paquímetro, utilizando-se a escala das figuras. O diâmetro médio de cada partícula foi estimado tomando-se a média entre duas medidas perpendiculares. Foram tomadas as medidas das esferas de menor e maior diâmetro.

\section{Resultados e discussão}

\subsection{Precipitado de inulina em pó}

O processo de secagem em spray dryer resultou em um pó fino e esbranquiçado, com umidade de $0,43 \%$, como pode ser observado na Figura 1.

\subsection{Análise da estabilidade da inulina em pó à temperatura ambiente: umidade de equilíbrio}

Uma vez que a inulina em pó possui uma baixa umidade inicial, houve uma absorção de água pelo produto em todas as condições ambientais, resultando em um acréscimo na umidade de equilíbrio, que variou de 0,0181 a 0,1944 (base seca). $\mathrm{Na}$ Tabela 2 são visualizados os valores médios de umidade de equilíbrio correspondentes às atividades de água do ambiente.

Devido às condições propícias proporcionadas pelo elevado teor de carboidratos da inulina e pela alta disponibilidade de

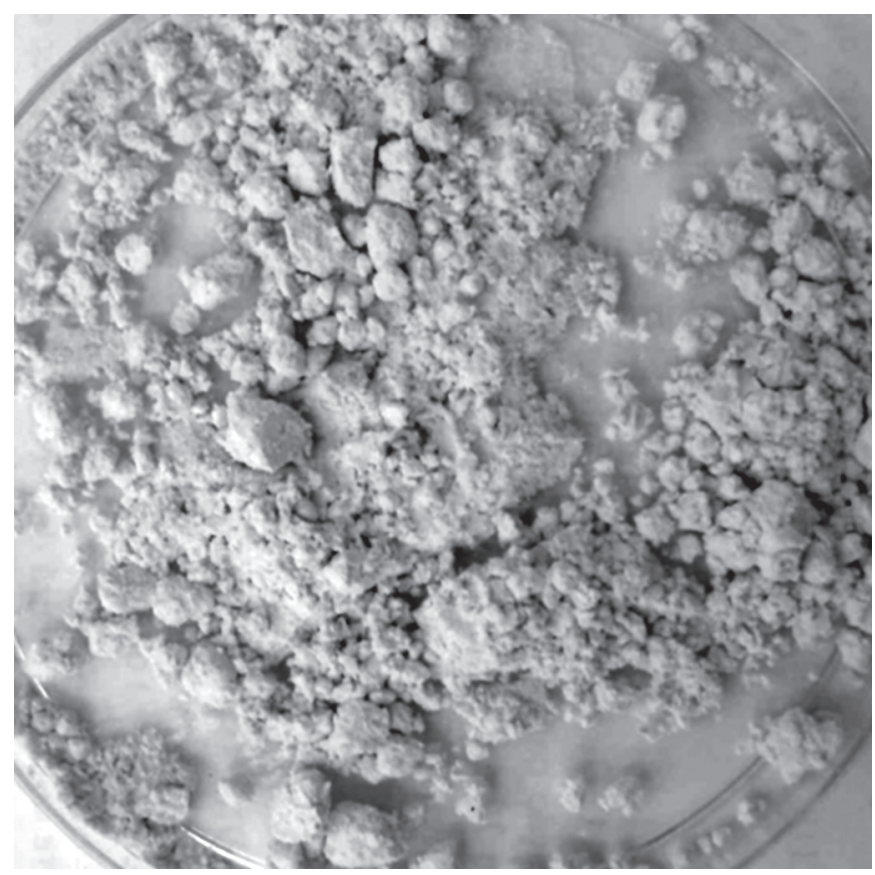

Figura 1. Precipitado de inulina em pó.

Tabela 1. Sais utilizados para o preparo das soluções saturadas e atividade de água correspondente, à temperatura de $25^{\circ} \mathrm{C}^{5}$.

\begin{tabular}{cccccccccc}
\hline Sal & $\mathrm{KOH}$ & $\mathrm{LiCl}$ & $\mathrm{KF}$ & $\mathrm{Mg}\left(\mathrm{NO}_{3}\right)_{2}$ & $\mathrm{NaBr}$ & $\mathrm{KI}$ & $\mathrm{Na}^{2}\left(\mathrm{NO}_{3}\right)^{2}$ & $\mathrm{KCl}$ & $\mathrm{KNO}_{3}$ \\
\hline $\mathrm{a}_{\mathrm{w}}$ & 0,0823 & 0,1130 & 0,3085 & 0,5289 & 0,5757 & 0,6886 & 0,7425 & 0,8099 & 0,9358 \\
\hline
\end{tabular}


água, os materiais armazenados em ambientes com atividade de água superior a 0,7425 foram contaminados por fungos antes que o equilíbrio fosse atingido, como pode ser observado na Figura 2.

A partir dos resultados apresentados na Tabela 2, foi traçada a isoterma de sorção da inulina em pó à temperatura de $25^{\circ} \mathrm{C}$ (Figura 3). A isoterma apresentou um formato sigmoidal típico de alimentos e materiais biológicos (tipo II), diferentemente dos açúcares cristalinos, que geralmente apresentam isotermas do tipo III (ROOS, 1995). Zimeri e Kokini (2002) e Ronkart et al. (2006) verificaram comportamento semelhante para as isotermas de sorção de inulina comercial, à temperatura de $25^{\circ} \mathrm{C}$.

As isotermas de sorção da inulina podem variar de acordo com o grau de polimerização (SCHALLER-POVOLNY; SMITH; LABUZA, 2000). Conforme a massa molecular efetiva diminui o comportamento muda, provavelmente devido ao fato de a

Tabela 2. Umidades de equilíbrio de inulina em pó armazenada sob diferentes condições de atividade de água, à temperatura de $25^{\circ} \mathrm{C}$.

\begin{tabular}{lcccc}
\hline \multicolumn{1}{c}{ Sal } & $\mathrm{a}_{\mathrm{w}}$ & \multicolumn{3}{c}{ Base seca } \\
\cline { 3 - 5 } & & $\begin{array}{c}\mathrm{XE} \\
\left(\mathrm{kg}_{\text {agua }} / \mathrm{kg}_{\mathrm{ms}}\right)\end{array}$ & $\mathrm{DP}$ & $\mathrm{CV}$ \\
\hline $\mathrm{KOH}$ & 0,0823 & 0,0181 & 0,0017 & $9,14 \%$ \\
$\mathrm{LiCl}$ & 0,1130 & 0,0278 & 0,0010 & $3,61 \%$ \\
$\mathrm{KF}$ & 0,3085 & 0,0668 & 0,0017 & $2,56 \%$ \\
$\mathrm{Mg}\left(\mathrm{NO}_{3}\right)_{2}$ & 0,5289 & 0,0899 & 0,0004 & $0,44 \%$ \\
$\mathrm{NaBr}$ & 0,5757 & 0,1068 & 0,0010 & $0,92 \%$ \\
$\mathrm{KI}$ & 0,6886 & 0,1185 & 0,0004 & $0,34 \%$ \\
$\mathrm{Na}(\mathrm{NO})_{3}$ & 0,7425 & 0,1298 & 0,0012 & $0,95 \%$ \\
$\mathrm{KCl}{ }^{\mathrm{a}}$ & 0,8099 & 0,1441 & 0,0024 & $1,65 \%$ \\
$\mathrm{~K}(\mathrm{NO})_{3}{ }^{a}$ & 0,9358 & 0,1944 & 0,0061 & $3,16 \%$ \\
\hline
\end{tabular}

${ }^{\mathrm{a} C}$ Condições em que a inulina foi contaminada por fungos.

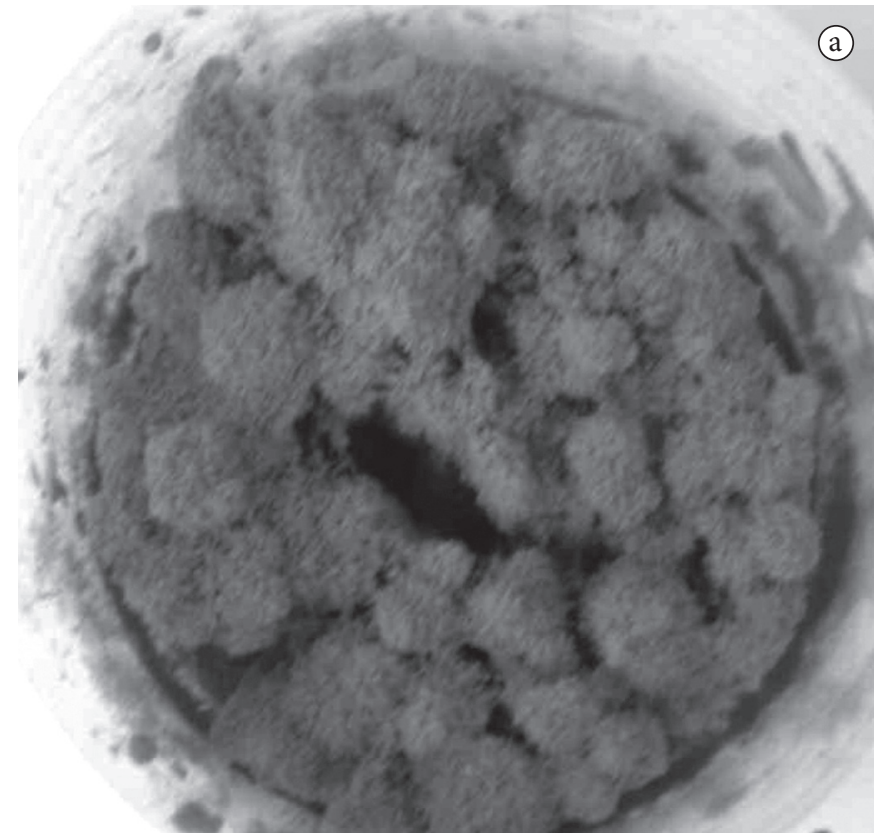

inulina ser enriquecida com frutose e sacarose, que possuem mais grupos hidroxi disponíveis para se ligar à água, movendo a forma sigmoidal da isoterma do tipo II para o tipo III (RONKART et al., 2006; SCHALLER-POVOLNY; SMITH; LABUZA, 2000).

Leite, Park e Ramalho (2002) e Nogueira (2001) determinaram as isotermas de sorção para amostras de inulina encapsuladas com amidos hidrolisados e modificados, avaliadas sob a temperatura de $25^{\circ} \mathrm{C}$, e verificaram um comportamento do tipo III, típico de açúcares. Berghofer et al. (1993) e Nogueira (2001) também determinaram a isoterma de sorção de sistemas de inulina em pó, à temperatura de $25^{\circ} \mathrm{C}$, e encontraram um comportamento semelhante. Nogueira (2001) observou umidades de equilíbrio com valores variando de 0,05 a $0,35 \mathrm{~g} \cdot \mathrm{g}^{-1}$ para atividades de água entre 0,11 e 0,75.

\subsection{Análise da microestrutura}

\section{Microestrutura do precipitado de inulina em pó}

Observando-se a Figura 1, onde é apresentada uma imagem macroscópica da inulina em pó, nota-se que a mesma se apresenta como um pó fino e esbranquiçado, com uma forte tendência à aglomeração, provavelmente devido à sua alta higroscopicidade. Analisando-se as Figuras 4a e b, onde são apresentadas suas imagens microscópicas, percebe-se que esse pó é formado por partículas esféricas de diâmetro variado. As esferas apresentam, em sua maioria, superfície lisa, havendo algumas partículas com leve rugosidade superficial. De acordo com Cano-Chauca et al. (2005), a presença de poucas fendas ou poros superficiais e a forte aderência das partículas menores em torno das maiores demonstra ausência de superfícies cristalinas e é característica de produtos amorfos.

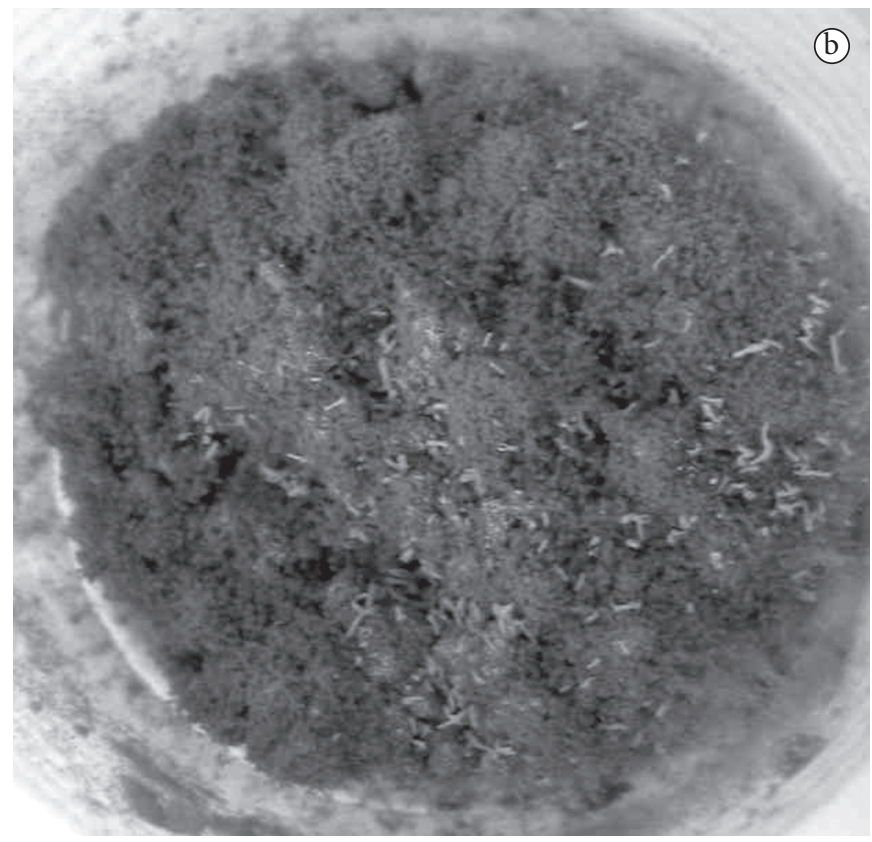

Figura 2. Amostras de inulina em pó contaminadas por fungos durante as análises de umidade de equilíbrio; a) $\left.\mathrm{KCl} / \mathrm{a}_{\mathrm{w}}=0,8099 ; \mathrm{e} b\right) \mathrm{K}(\mathrm{NO}){ }_{3} /$ $\mathrm{a}_{\mathrm{w}}=0,9358$. 


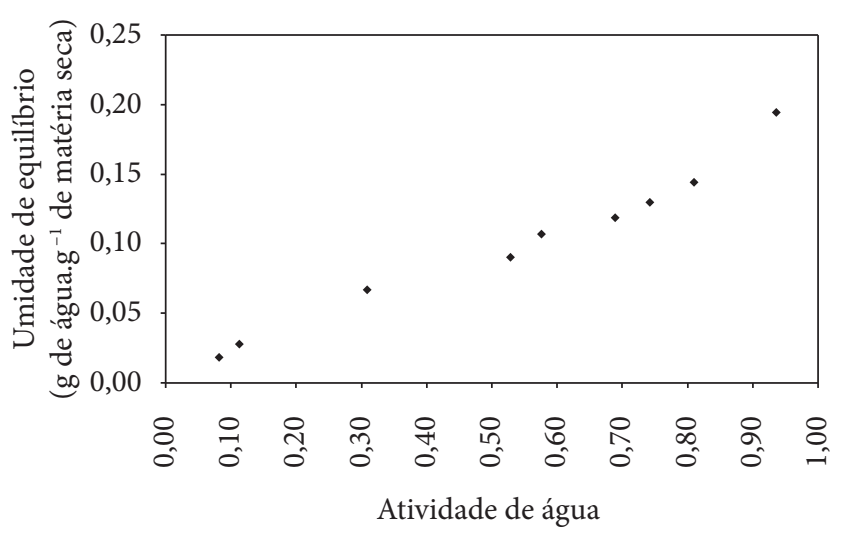

Figura 3. Isoterma de sorção da inulina em pó à temperatura de $25^{\circ} \mathrm{C}$.
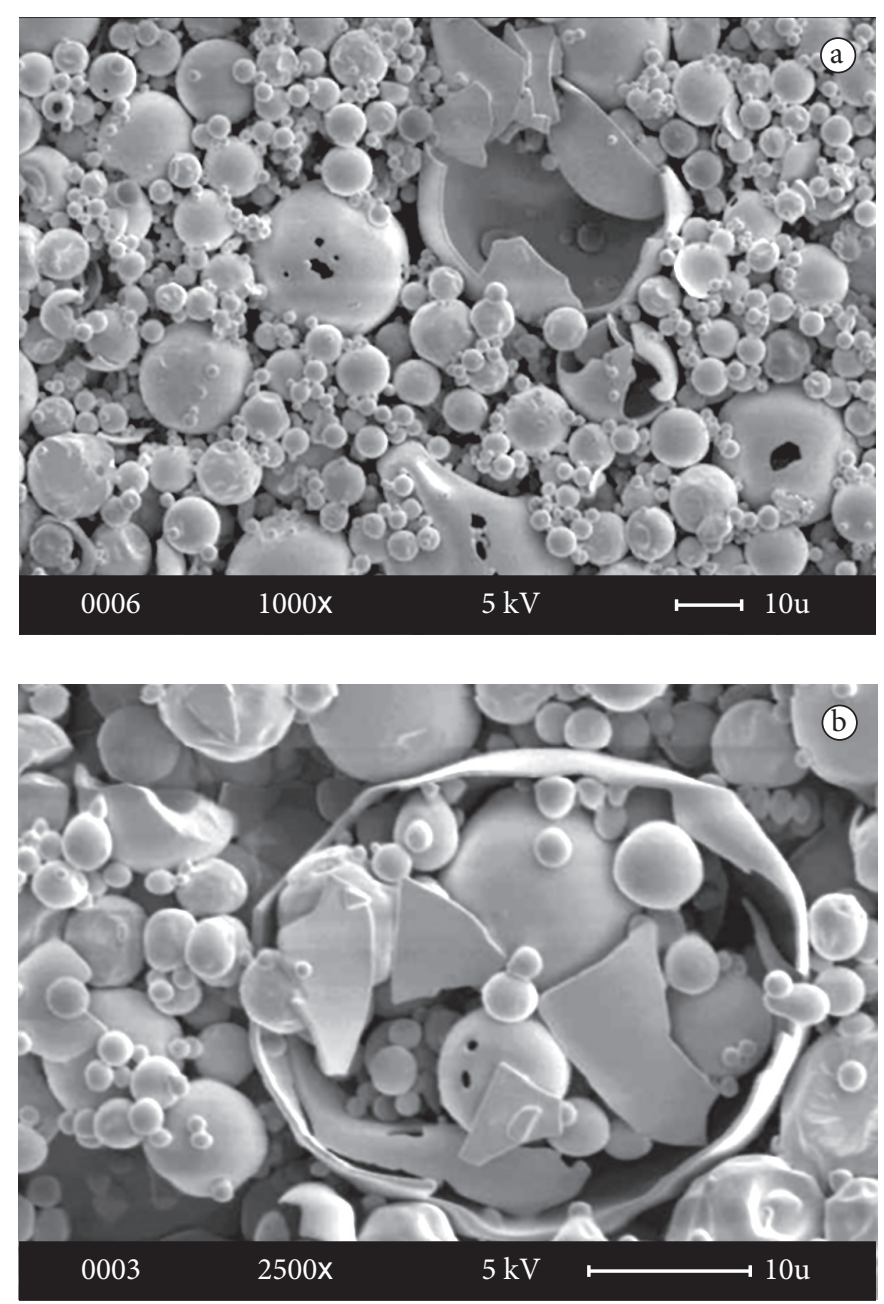

Figura 4. Imagens macroscópicas e microscópicas do pó resultante do processo de secagem de precipitado de inulina em spray dryer laboratorial; a) Imagem com aumento de 1000x; e b) Imagem com aumento de 2500x.

Ronkart et al. (2006) observaram a microestrutura de inulina comercial em pó (marca Warcoing - Bélgica) e a definiram como formas esféricas amorfas, com tamanho médio variável entre 50 e $100 \mu \mathrm{m}$. Leite, Park e Ramalho (2002) estudaram a microestrutura de inulina em pó, obtida através da secagem de precipitado de inulina em spray dryer laboratorial e com temperaturas de ar de secagem entre 186 e $193{ }^{\circ} \mathrm{C}$. Os autores observaram que o precipitado de inulina em pó apresentou partículas esféricas de tamanho variado, com uma tendência à aglomeração das partículas de menor diâmetro em torno das maiores, além de uma grande quantidade de partículas com superfície rugosa.

Nogueira (2001) estudou o efeito das temperaturas de entrada e de saída do ar de secagem e da adição de agentes encapsulantes sobre a microestrutura de inulina em pó e observou que os produtos que foram secos à temperatura de entrada de $130^{\circ} \mathrm{C}$ apresentaram microestrutura com tendência à formação de esferas de diferentes tamanhos, mas com muitas rugas em toda extensão da superfície. Aumentando-se a temperatura para $200^{\circ} \mathrm{C}$, com uma temperatura de saída de $119^{\circ} \mathrm{C}$, a autora observou a formação das mesmas estruturas esféricas, porém, com superfície externa mais homogênea, apresentando apenas uma leve rugosidade.

A formação de superfícies rugosas é uma característica indesejável e muito freqüente em polímeros. De acordo com Rosenberg, Kopelman e Talmon (1985), a formação de microestruturas deste tipo afeta as condições de escoamento do material.

$\operatorname{Re}$ (1998) relata que as imperfeições superficiais - como rugosidades, fissuras ou colapso - ocorrem quando há um lento processo de formação de filme durante a secagem das gotículas atomizadas. $\mathrm{O}$ aumento da temperatura de secagem, por sua vez, aumenta a taxa de formação de filme na superfície da gota. $\mathrm{O}$ autor associa a presença de dentes superficiais ao colapso sofrido pelas gotículas nos primeiros estágios do processo de secagem.

Dessa maneira, pode-se atribuir a maior formação de superfícies rugosas às menores temperaturas de secagem. Por essa razão, as partículas de precipitado de inulina em pó observadas por Leite, Park e Ramalho (2002), que foram secas sob temperaturas inferiores a $193^{\circ} \mathrm{C}$, mostraram maior rugosidade superficial do que as apresentadas na Figura 4, que foram secas à temperatura de $210^{\circ} \mathrm{C}$.

No detalhe apresentado na Figura 4b, observa-se a formação de uma partícula oca, com esferas de menor diâmetro envoltas por ela. Esse tipo de estrutura foi relatada nos trabalhos de Nogueira (2001) e Leite, Park e Ramalho (2002), no estudo da secagem em spray dryer de suspensões compostas por inulina e amidos modificados e hidrolisados, os quais foram aplicados para exercer a função de agentes encapsulantes. $\operatorname{Re}(1998)$ atribui a formação dessas grandes esferas ocas à expansão das partículas durante os últimos estágios do processo de secagem.

Não há estudos relacionando a qualidade da inulina em pó ao tamanho ou ao formato das partículas. No entanto, são desejáveis partículas com poucas imperfeições superficiais, o que garantirá uma maior escoabilidade do produto.

Arshadi (1993) relata que a influência do tamanho da microcápsula sobre a estabilidade de alguns ingredientes ainda não foi claramente explicada, embora estudos tenham estabelecido 
que há um tamanho ótimo, tanto para a retenção quanto para a estabilidade do ingrediente nas microcápsulas; sendo que a queda na estabilidade pode ser devido a um maior grau de imperfeição de suas superfícies conforme estas aumentam.

\section{Influência da umidade sobre a microestrutura}

O precipitado de inulina em pó armazenado sob diferentes condições de umidade relativa, à temperatura de $25^{\circ} \mathrm{C}$, foi avaliado em microscópio eletrônico de varredura para verificar a influência da umidade sobre a sua estrutura.

Quando armazenado em ambientes com atividade de água de até 0,3085 , observou-se pouca alteração na estrutura do precipitado de inulina em pó, como pode ser observado na Figura 5. O ganho de umidade resultou em uma maior aglomeração das partículas de menor diâmetro em torno das maiores (Figura 5b), que se refletiu em um empelotamento do material
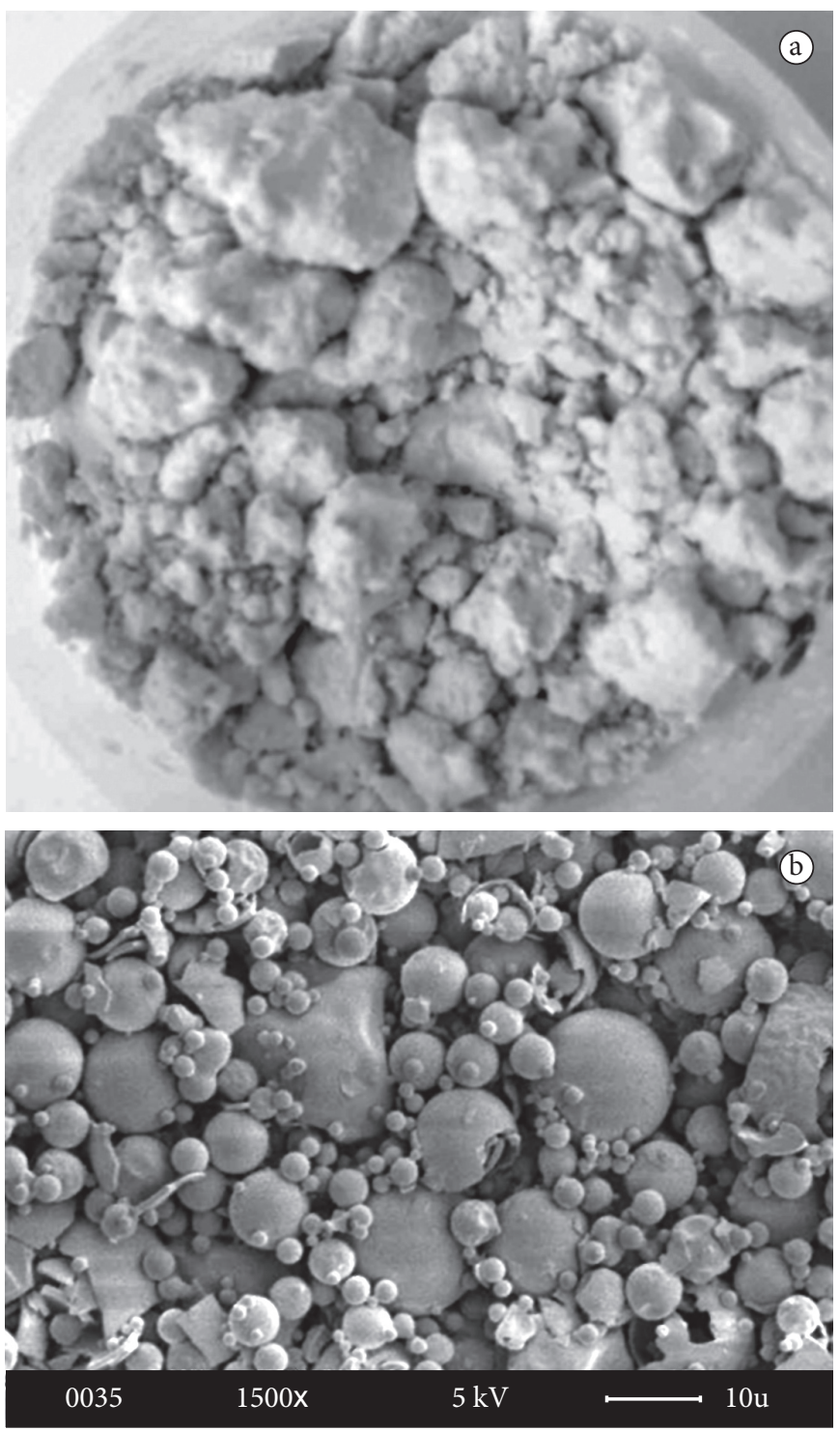

Figura 5. Imagens macroscópicas e microscópicas da inulina em pó mantida em ambiente com $\mathrm{a}_{\mathrm{w}}=0,3085$ até o equilíbrio em $6,26 \%$ de umidade; a) Imagem macroscópica; e b) Imagem com aumento de 1500x.
(Figura 5a). Essa característica é indesejável, pois interfere na escoabilidade do pó. No entanto, apesar do ganho de umidade, as alterações na microestrutura do material ainda não são muito pronunciadas.

Quando o precipitado de inulina em pó é armazenado em ambiente com $\mathrm{a}_{\mathrm{w}}=0,5289$, ele absorve umidade até $8,25 \%$ e sofre grandes alterações em sua estrutura, como pode ser observado na Figura 6. O ganho de apenas $2 \%$ de umidade, em relação ao material armazenado em ambiente com $\mathrm{a}_{\mathrm{w}}=0,3085$ (Figura 5), provoca a total aglomeração das partículas, havendo a formação de pontes entre as microesferas, como pode ser observado na Figura $6 \mathrm{~b}$. Nos detalhes apresentados nas Figuras $6 \mathrm{c}$, d, notase que os espaços vazios no interior das microesferas já estão praticamente preenchidos, havendo algumas raras concavidades de pouca profundidade.

Observando-se a Figura 6a, fica claro que a aglomeração das partículas provoca uma total alteração nas características macroscópicas do precipitado de inulina em pó. A umidade absorvida provoca uma aglomeração do material, que perde as suas características de pó e passa a ser uma massa sólida e dura, formada pela união de unidades menores. Observa-se ainda uma mudança na coloração do material, que passa de esbranquiçada para caramelada, aproximando-se da cor inicial do precipitado de inulina.

Zimeri e Kokini (2002) estudaram a influência da umidade sobre a cristalinidade da inulina comercial em pó. Os autores observaram que, quando a inulina em pó é armazenada em ambientes com umidade relativa elevada, há um aumento na mobilidade do sistema, facilitada pela absorção de água, que favorece a reorganização do material em uma forma cristalina e mais estável. A absorção de água reduz a temperatura de transição vítrea do material, e quando ele é armazenado em temperaturas superiores à sua $\mathrm{T}_{\mathrm{g}}$, ocorre a recristalização. Esses autores determinaram que, à temperatura ambiente, a transição vítrea da inulina ocorre a uma umidade de $18 \%$ em base seca, correspondendo a ambientes com a próxima a 0,75 .

A partir da umidade relativa de 0,5289, a absorção de maiores quantidades de água pelo precipitado de inulina em pó resultou em uma maior aglomeração das partículas, tornando-o uma massa sólida, na qual não é mais possível distinguir as microesferas iniciais. Na Figura 7, pode-se observar as estruturas macroscópica e microscópica do precipitado de inulina em pó após armazenagem em ambientes com atividade de água de $0,5289,0,6886$ e 0,7425. Analisando-se a imagem da Figura $7 b$, percebe-se que os pequenos aglomerados iniciais, formados pelas pontes de ligação, passam a ser uma estrutura única, na qual é possível perceber, em um aumento de 1500 vezes, apenas algumas linhas estreitas, indicando os limites superficiais entre as estruturas originais.

Pela Figura 7, observa-se que para umidades superiores a $10,5 \%$ já não é mais possível distinguir as microesferas iniciais, mesmo para aumentos de 1500 vezes. A aparência porosa da superfície é o único indício da estrutura inicialmente esférica do pó, que se transformou em uma massa sólida e escura.

A análise das imagens macroscópicas e microscópicas do precipitado de inulina em pó armazenado em ambientes com 

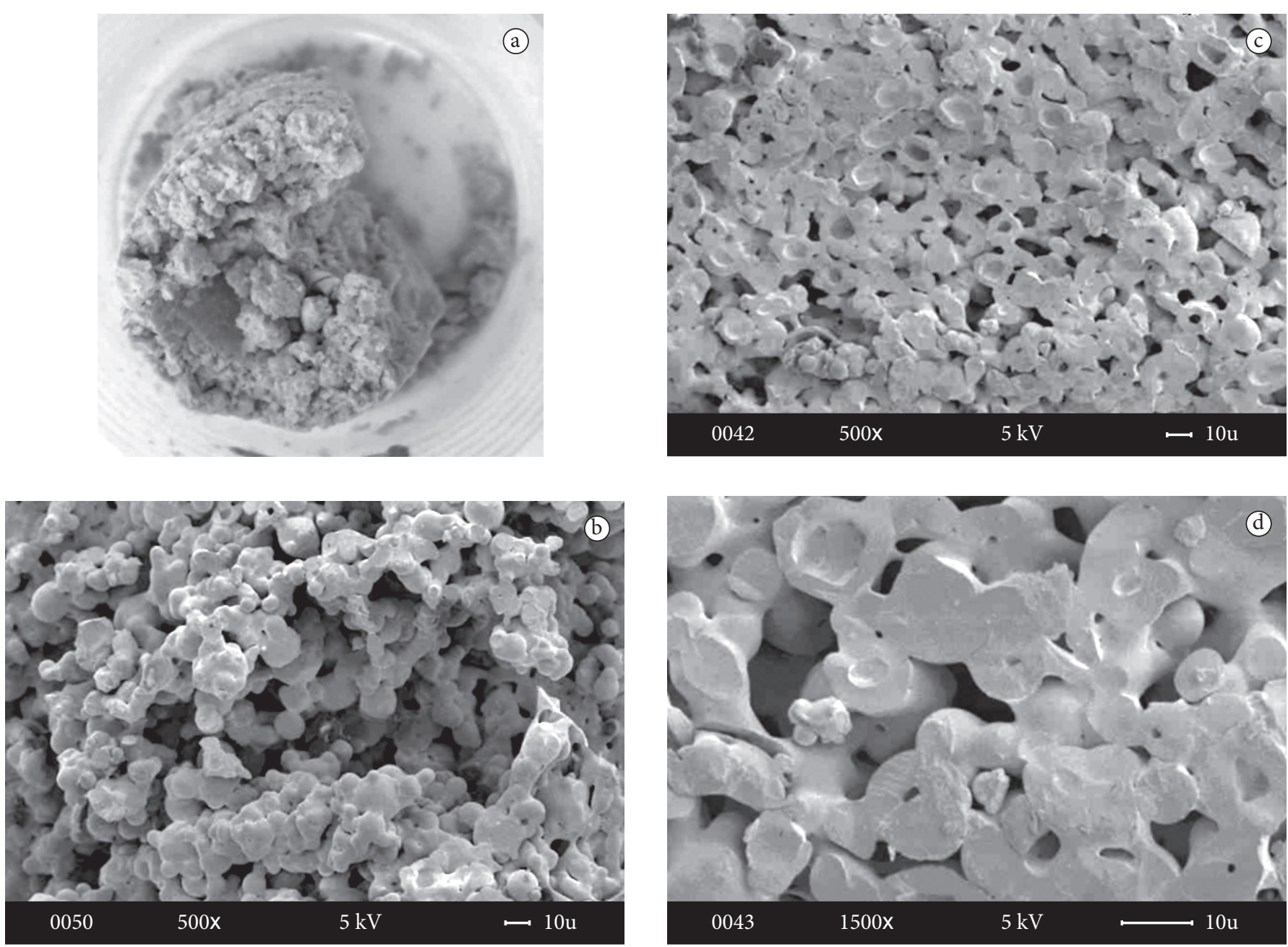

Figura 6. Imagem macroscópica e imagens microscópicas da inulina em pó mantida em ambiente com $\mathrm{a}_{\mathrm{w}}=0,5289$ até o equilíbrio em $8,25 \%$ de umidade; a) Imagem macroscópica; b) Imagem com aumento de 500x; c) Imagem com aumento de 500x; e d) Imagem com aumento de 1500x.

diferentes atividades de água, à temperatura de $25{ }^{\circ} \mathrm{C}$, leva à conclusão de que em ambientes com $\mathrm{a}_{\mathrm{w}}$ superior a 0,3085 , o material sofre alterações em sua microestrutura e que estas comprometem a sua qualidade de maneira irreversível. Ao atingir a umidade de $8,25 \%$, quando armazenado em ambiente com $\mathrm{a}_{\mathrm{w}}=0,5285$, o material perde suas características de pó devido ao empelotamento associado à absorção de umidade, e se transforma em uma massa sólida, formada pela aglomeração de unidades menores. Essa característica é agravada conforme há um aumento da umidade relativa do ambiente.

Quando a inulina é armazenada em ambientes com $\mathrm{a}_{\mathrm{w}}$ superior a 0,7425 , a sua qualidade é ainda mais comprometida devido ao aparecimento de fungos que provocam a total deterioração do material.

Em ambientes com $a_{w}$ inferior a 0,3085 , a máxima umidade atingida pela inulina em pó foi de $6,26 \%$, o que provocou uma leve aglomeração das partículas de menor diâmetro em torno das maiores. Essa característica é indesejável por afetar as características do produto, como a escoabilidade, por exemplo, porém, não se pode afirmar que nesse caso houve uma alteração irreversível na estrutura do material.

Os resultados obtidos estão de acordo com Ronkart et al. (2006), que observaram amostras de inulina comercial em pó armazenadas em ambientes com diferentes umidades relativas. Para atividades de água de até 0,33 , à temperatura de $20^{\circ} \mathrm{C}, \mathrm{o}$ material permaneceu sob a forma de pó. Entretanto, a partir de uma atividade de água de 0,56 , o produto encolhe e forma uma massa aglomerada de coloração branca e brilhante. Esse comportamento também foi reportado por Schaller-Povolny, Smith e Labuza (2000) para inulina comercial para atividades de água a partir de 0,54 .

Ronkart et al. (2006) avaliaram a microestrutura das amostras de inulina após armazenagem sob diferentes condições de umidade relativa, à temperatura de $20^{\circ} \mathrm{C}$, e também observaram a formação de uma massa contínua para ambientes com atividade de água igual ou superior a 0,56 . Os autores concluíram que a absorção de água provocou uma queda na temperatura de transição vítrea abaixo da temperatura de armazenagem, 

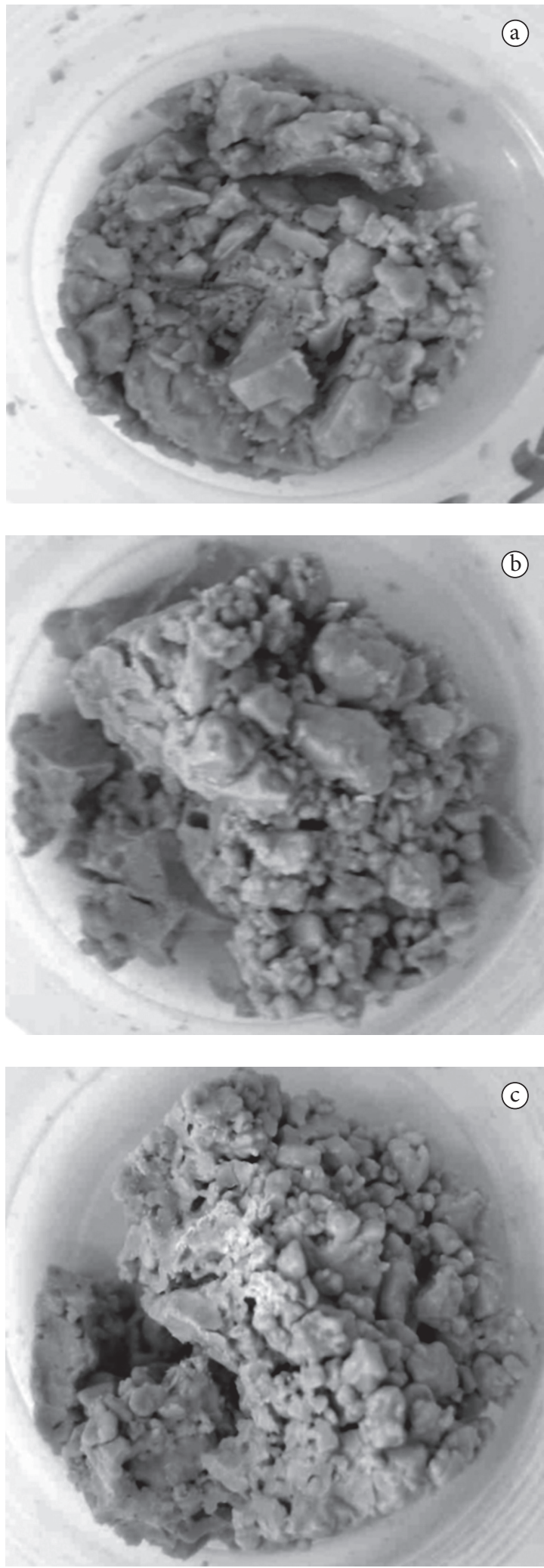
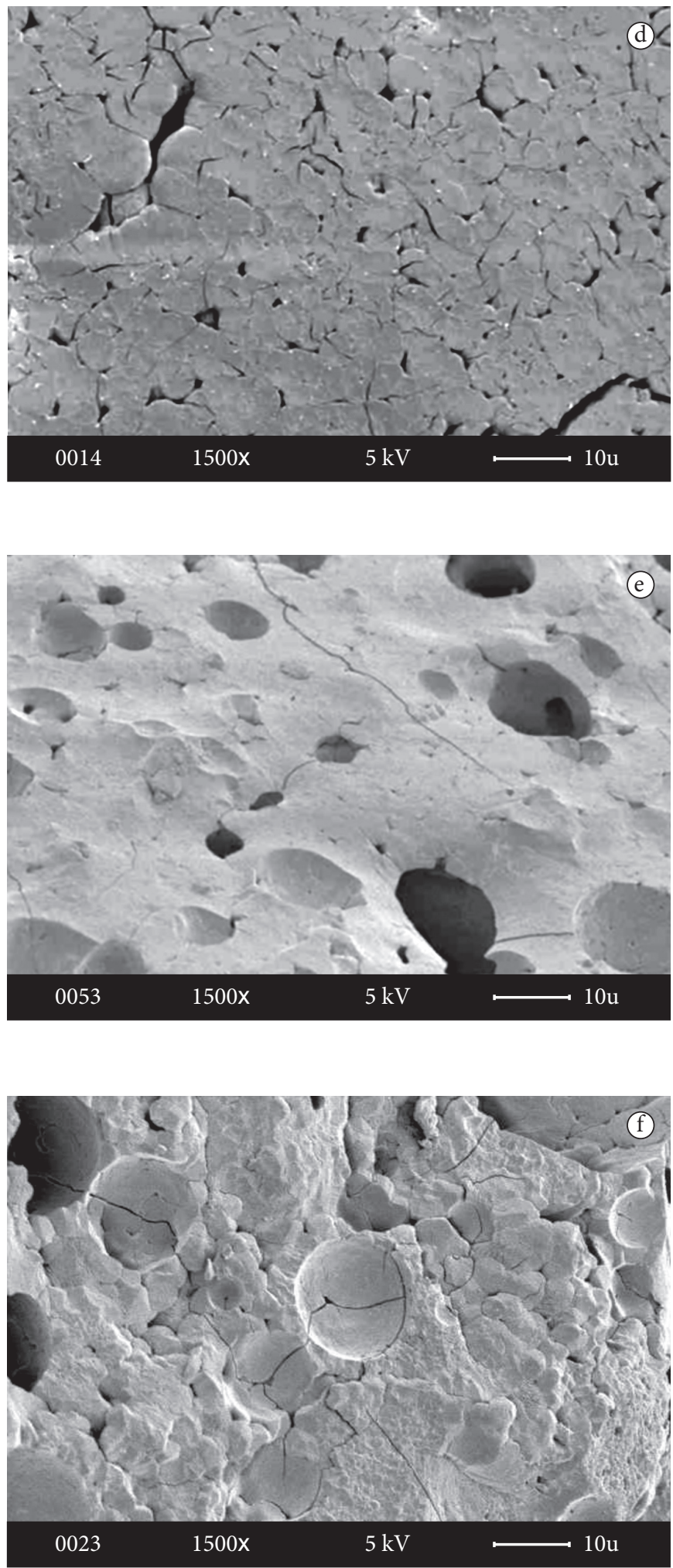

Figura 7. Imagem macroscópica e imagens microscópicas da inulina em pó mantida em ambientes com atividades de água de $0,5289,0,6886$ e 0,7425 ; a) Imagem macroscópica $a_{w}=0,5757 / X E=9,68 \%$; b) Imagem macroscópica $a_{w}=0,6886 / X E=10,60 \%$; ) Imagem macroscópica $\mathrm{a}_{\mathrm{w}}=0,7425 / \mathrm{XE}=11,49 \%$; $)$ Aumento de $1500 \mathrm{x} \mathrm{a}_{\mathrm{w}}=0,5289 / \mathrm{XE}=9,68 \%$; e) Aumento de $1500 \mathrm{x} \mathrm{a}_{\mathrm{w}}=0,6886 / \mathrm{XE}=10,60 \%$; e f) Aumento de 1500x $\mathrm{a}_{\mathrm{w}}=0,7425 / \mathrm{XE}=11,49 \%$. 
levando ao desenvolvimento da cristalinidade entre as partículas amorfas, o que causou a aglomeração do material.

\section{Diâmetro médio das partículas}

Os valores do diâmetro médio das partículas, assim como os valores dos diâmetros máximo e mínimo, observados nas imagens, estão apresentados na Tabela 3.

A partir dos resultados apresentados na Tabela 3, observase que o processo de secagem de precipitado de inulina em pó por spray dryer produziu um pó com um diâmetro médio de 2,20 $\mu \mathrm{m}$, sendo que o coeficiente de variação em torno da média foi de $73,16 \%$. O valor máximo observado foi de 9,71 e o mínimo $0,74 \mu \mathrm{m}$. Esse resultado demonstra que há uma grande variabilidade nos diâmetros das partículas formadas pela secagem em spray dryer laboratorial.

Nogueira (2001) observou que a secagem de extrato concentrado de inulina em spray dryer laboratorial, à temperatura de $165^{\circ} \mathrm{C}$, produziu partículas esféricas com diâmetro variável de 1,46 a 15,12 $\mu \mathrm{m}$. Leite, Park e Ramalho (2002) observaram que a secagem de precipitado de inulina por atomização, sob temperaturas entre 186 e $193{ }^{\circ} \mathrm{C}$, produziu partículas esféricas com um diâmetro médio de 2,83 $\mu \mathrm{m}$, variando de 0,76 a 18,46 $\mu \mathrm{m}$.

Os resultados apresentados na Tabela 5 indicam ainda, que a absorção de umidade provocou um leve aumento no diâmetro médio, que passou de 2,20 $\mu \mathrm{m}$ para uma faixa de 2,8 a 3,3 $\mu \mathrm{m}$. No entanto, não é possível estabelecer uma correlação entre a umidade e o diâmetro, já que há uma variabilidade muito grande dentro de uma mesma amostra. Esse aumento também é observado nos valores máximos e mínimos, que passaram de 0,74 e 9,71 para até 1,14 e 14,16 $\mu \mathrm{m}$.

\section{Conclusões}

O precipitado de inulina, após secagem em spray dryer, se apresentou como um pó de coloração esbranquiçada, com microestrutura formada por partículas esféricas de diâmetro variável entre 0,74 e $9,71 \mu \mathrm{m}$. A estrutura superficial das micropartículas é predominantemente lisa, havendo algumas estruturas com leves rugosidades superficiais.

$\mathrm{O}$ armazenamento do precipitado de inulina em pó em ambientes com atividade de água variável de 0,0823 a 0,7425, à temperatura de $25^{\circ} \mathrm{C}$, resultou na absorção de umidade pelo material. A isoterma de sorção para essas condições foi do tipo II.

A armazenagem do precipitado de inulina em pó em ambiente com atividade de água de 0,3085 resultou em ganho de umidade até o nível de 6,26\%, provocando um leve aumento no diâmetro médio. Para níveis superiores a esse valor, houve alterações estruturais no material devido à aglomeração de partículas, provocada pela absorção de água.

\section{Agradecimentos}

À Fundação de Amparo à Pesquisa do Estado de São Paulo (FAPESP), ao Conselho Nacional de Desenvolvimento Científico e Tecnológico ( $\mathrm{CNPq})$, à Faculdade de Engenharia Agrícola (FEAGRI/UNICAMP) e à Faculdade de Engenharia de Alimentos (FEA/UNICAMP).

\section{Referências bibliográficas}

ARSHADI, R. Microcapsules for food. Journal of Microencapsulation. London, v. 10, n. 4, p. 413-435, 1993.

ASSOCIATION OF OFFICIAL ANALYTICAL CHEMISTS. Official methods of analysis of A.O.A.C. international. 16. ed. Arlington: A.O.A.C., Inc. 1995.

BERGHOFER, E. et al. Pilot-scale production of inulin from chicory roots and its use in foodstuffs. OIn: FUCHS, A. (Ed.), Inulin and inulin containing crops. Amsterdam: Elsevier Science Ltd., 1993. p. 77-84.

CANO-CHAUCA, M. et al. Effect of the carriers on the microstructure of mango powder obtained by spray drying and its functional characterization. Innovative Food Science \& Emerging Technologies, Oxford, v. 6, n. 4, p. 420-428, 2005.

GREENSPAN, L. Humidity fixed points of binary saturated aqueous solutions. Journal of Research of the National Bureau of Standards - A. Physics and Chemistry. Washington, v. 81A, n. 1, p. 89-96. 1977.

LAURENZO, K. S.; NAVIA; J. L.; NEIDITCH; D. S. Preparation of inulin products. USA Patent number 5,968,365. oct. 19, 1999.

LEITE, J. T. C. Obtenção de extrato de inulina de chicória (Cichorium intybus) por abaixamento de temperatura e secagem por spray dryer. Campinas, 2001. 112p. Dissertação (mestrado em Engenharia Agrícola) - Faculdade de Engenharia Agrícola, Universidade Estadual de Campinas, Campinas.

LEITE, J. T. C.; PARK, K. J.; RAMALHO, J. R. P. Isotermas de sorção e modelagem matemática da inulina em pó. In: Congresso Brasileiro de Ciência e Tecnologia de Alimentos, 18, 2002, Porto Alegre. Anais... XVIII Congresso Brasileiro de Ciência e Tecnologia de Alimentos. Porto Alegre: Sociedade Brasileira de Ciência e Tecnologia de Alimentos. 2002a. OU864. CD ROM.

. Análise da microestrutura de inulina em pó por microscopia eletrônica de varredura. In: Congresso Brasileiro de Ciência e Tecnologia de Alimentos, 18, 2002, Porto Alegre. Anais... XVIII Congresso Brasileiro de Ciência e Tecnologia de Alimentos. Porto Alegre: Sociedade Brasileira de Ciência e Tecnologia de Alimentos. 2002b. OU868. CD ROM.

Tabela 3. Diâmetros máximo, mínimo e médio observados nas imagens microscópicas de precipitado de inulina em pó com diferentes umidades.

\begin{tabular}{|c|c|c|c|c|c|c|c|}
\hline Amostra & $a_{w}$ & $\begin{array}{l}\text { Umidade } \\
(\%)\end{array}$ & $\begin{array}{l}\text { Diâmetro } \\
\text { médio }(\mu \mathrm{m})\end{array}$ & $\begin{array}{c}\text { Desvio padrão } \\
(\mu \mathrm{m})\end{array}$ & CV (\%) & $\begin{array}{c}\text { Diâmetro } \\
\text { máximo }(\mu \mathrm{m})\end{array}$ & $\begin{array}{c}\text { Diâmetro } \\
\text { mínimo }(\mu \mathrm{m})\end{array}$ \\
\hline Inulina condição ótima & - & 0,43 & 2,20 & 1,61 & 73,16 & 9,71 & 0,74 \\
\hline Inulina armazenada em $\mathrm{KOH}$ & 0,0823 & 1,78 & 3,20 & 2,54 & 79,24 & 13,91 & 0,80 \\
\hline Inulina armazenada em $\mathrm{LiCl}$ & 0,1130 & 2,70 & 3,30 & 2,67 & 80,88 & 14,16 & 1,14 \\
\hline Inulina armazenada em KF & 0,3085 & 6,26 & 2,82 & 1,98 & 70,19 & 11,21 & 0,97 \\
\hline
\end{tabular}


NOGUEIRA, R. I. Processo de obtenção de inulina de chicória (Cichorium intybus) em pó. Campinas, 2001. 104p. Tese (Doutorado em Engenharia Agrícola)- Faculdade de Engenharia Agrícola, Universidade Estadual de Campinas, Campinas.

O'BRIEN, C. M. et al. Evaluation of the effects of fat replacers on the quality of wheat bread. Journal of Food Engineering. Oxford, v. 56, n. 2-3, p. 265-267, 2003.

PARK, K. J. et al. Processo de obtenção de concentrado de inulina por abaixamento de temperatura e separação física. BR Patente número PI 0003867-9. 17 ago. 2000.

RE, M. I. Microecapsulation by spray drying. Drying technology. New York, v. 16, n. 6, p. 1195-1236. 1998.

ROBINSON, R. K. The potential of inulin as a functional ingredient. British Food Journal. Bradford, v. 97, n. 4, p. 30-32. 1995.

RONKART, S. et al. Determination of physical changes of inulin related to sorption isotherms: An X-ray diffraction, modulated differencial scanning calorimetry and environmental scanning electron microscopy study. Carbohydrate Polymers. Oxford, v. 63, n. 2, p. 210-217, 2006.

ROOS, Y. H. Phase transitions in foods. San Diego, California: Academic Press. 1995. 362p.
ROSENBERG, M.; KOPELMAN, I. J.; TALMON, Y. A Scanning electron microscopy study of microencapsulation. Journal of Food Science. Bradford, v. 50, n. 1, p. 139-144, 1985.

SCHALLER-POVOLNY, L. A.; SMITH, D. E.; LABUZA, T. P. Effect of water content and molecular weight on the moisture isotherms and gleass transition properties of inulin. International Journal of Food Properties. New York, v. 3, n. 2, p. 173-192, 2000.

SILVA, R. F. Use of inulin as a natural texture modifier. Cereal Foods World. St Paul, v. 41, n. 10, p. 792-795, 1996.

TONELI, J. T. C. L. Processos de separação física e secagem de inulina obtida a partir de raiz de chicória (Cichorium intybus L.). Campinas, 2006. 177p. Tese (doutorado em Engenharia de Alimentos) - Faculdade de Engenharia de Alimentos, Universidade Estadual de Campinas, Campinas.

TONELI, J. T. C. L. et al. Optimization of a physical concentration process for inulin. Journal of Food Engineering. Oxford, v. 80, n. 3, p. 832-838, 2006.

ZIMERI, J. E.; KOKINI, J. L. The effect of moisture content on the crystallinity and glass transition temperature of inulin. Carbohydrate Polymers. Oxford, v. 48, n. 3, p. 299-304. 2002. 